\title{
Aetiology
}

\section{Review: ambulatory blood pressure monitoring predicts clinical outcomes}

Appel LJ, Robinson KA, Guallar E, et al. Utility of blood pressure monitoring outside of the clinic setting. Evidence Report/Technology Assessment no 63. AHRQ publication no 03-E004 Rockville, MD:Agency for Healthcare Research and Quality, Nov 2002.http://www.ahrq.gov/clinic/bpmoninv.htm

\section{QUESTION: Does blood pressure (BP), either self measured (SMBP) or measured by ambulatory monitoring (AMBP) outside a clinical setting, predict clinical outcomes?*}

\section{Data sources}

Studies were identified by searching 3 electronic databases and hand searching journals, reference lists, and conference proceedings.

\section{Study selection}

Longitudinal studies fully published in English were selected if they reported on AMBP or SMBP in $\geq 50$ patients.

\section{Data extraction}

Data were extracted on study design and setting, method of BP measurement, time and place of BP measurement, and outcomes

A

Research and Quality.

For correspondence: Dr LJ Appel, Johns

Hopkins

Evidence-based Practice

Center, Baltimore, $M D$,

USA.lappel@jhmi.edu

\section{Main results}

1 prospective cohort study tested the association between SMBP and total and cardiovascular disease (CVD) deaths at 6.6 years $(\mathrm{n}=1728)$ and between SMBP and fatal and non-fatal stroke at 4.4 years $(n=1256)$ (table).

Associations between blood pressure measurements and clinical outcomes*

\begin{tabular}{|c|c|c|c|}
\hline $\begin{array}{l}\text { Type of blood pressure } \\
\text { measurement }\end{array}$ & Clinical outcome & $\begin{array}{l}\text { Number of } \\
\text { studiest }\end{array}$ & Relative risk range \\
\hline \multirow[b]{2}{*}{ Systolic SMBP } & CVD death & 1 of 1 & 1.02 \\
\hline & All deaths & 1 of 1 & 1.01 \\
\hline Diastolic SMBP & Stroke & 1 of 1 & $3.12 \ddagger$ \\
\hline \multirow[b]{4}{*}{ Daytime systolic AMBP } & CVD death & 1 of 3 & 1.3 \\
\hline & CVD death/morbidity & 3 of 4 & $1.19-6.42$ \\
\hline & Stroke & 2 of 2 & $1.41-1.51$ \\
\hline & All deaths & 0 of 2 & Not significant \\
\hline \multirow[b]{4}{*}{ Night-time systolic AMBP } & CVD death & 2 of 3 & $1.41-1.42$ \\
\hline & CVD death/morbidity & 2 of 2 & $1.31-1.34$ \\
\hline & Stroke & 2 of 2 & $1.30-1.34$ \\
\hline & All deaths & 1 of 2 & 1.24 \\
\hline \multirow[b]{4}{*}{24 hour systolic AMBP } & CVD death & 1 of 3 & 1.34 \\
\hline & CVD death/morbidity & 4 of 4 & $1.03-1.28$ \\
\hline & Stroke & 2 of 2 & 1.47 and 1.47 \\
\hline & All deaths & 1 of 2 & 1.23 \\
\hline \multirow[b]{4}{*}{ Daytime diastolic AMBP } & CVD death & 0 of 1 & Not significant \\
\hline & CVD death/morbidity & 1 of 3 & 2.46 \\
\hline & Stroke & 1 of 1 & 1.31 \\
\hline & All deaths & 0 of 1 & Not significant \\
\hline \multirow{4}{*}{$\begin{array}{l}\text { Night-time diastolic } \\
\text { AMBP }\end{array}$} & CVD death & 0 of 1 & Not significant \\
\hline & CVD death/morbidity & 1 of 2 & 1.67 \\
\hline & Stroke & 1 of 1 & 1.24 \\
\hline & All deaths & 0 of 1 & Not significant \\
\hline \multirow[b]{3}{*}{24 hour diastolic AMBP } & CVD death & 0 of 1 & Not significant \\
\hline & CVD death/morbidity & 1 of 2 & 1.71 \\
\hline & All deaths & 0 of 1 & Not significant \\
\hline
\end{tabular}

*AMBP = ambulatory monitoring blood pressure; $\mathrm{CVD}=$ cardiovascular; $\mathrm{SMBP}=$ self measured blood pressure. tNumber of studies showing a significant association $(p<0.05)$.

† Number of studies showing a significant association $(p<0.05)$.
10 prospective cohort studies assessed the relation between AMBP and clinical outcomes (table). Follow up ranged from $1-6.4$ years.

\section{Conclusions}

In 10 prospective studies, $\geq 1$ dimension of blood pressure measured by ambulatory monitoring predicts clinical outcomes. Only 1 study has tested the association between self measured blood pressure and clinical outcomes.

* The report addressed other questions not reported in this abstract.

\section{COMMENTARY}

Until this review by Appel $e t$ al, clinicians did not know what to make of $\mathrm{ABP}$ because evidence on prognosis had not been consolidated. ABP is a non-invasive automated technique measuring $\mathrm{BP}$ at intervals usually over a 24 hour period. ABP can identify absolute BP, white coat hypertension (WCH), non-dipping (night-time $\mathrm{BP}<10 \%$ lower than daytime BP), and reverse dipping (night-time $\mathrm{BP}$ higher than davtime $\mathrm{BP}$ ). Most people are nocturnal dippers. Their systolic BP (SBP) and diastolic BP (DBP) drop about 10-20\% compared with average daytime levels.

Appel et al have structured this 235 page evidence-based report to answer key questions on the management of this epidemic of hypertension affecting $25 \%$ of the US population. Higher ABP levels and patterns in cross-sectional studies were confirmed to be positively associated with BP related target organ damage. In prospective ABP studies, higher sustained BP and non-dipping or reverse dipping patterns were positively associated with increased risk of CVD events, highly so for secondary hypertension as in end stage renal disease and type 2 diabetes.

ABP is useful for diagnosing WCH, comprising approximately $20 \%$ of hypertensive patients. WCH predicts a reduced CVD risk compared with sustained hypertension. ${ }^{1}$ The question of whether risk in WCH is equivalent to risk in normotension, or whether to withhold drug therapy, cannot be answered by Appel $e t$ al because of insufficient reported data. For SMBP, although half of reviewed studies confirmed an association of its use with reduced BP, no conclusion could be made between its use and reduced CVD outcome, again because of insufficient published data.

Health funders in the US are now incorporating these data in decision making by using $\mathrm{ABP}$ to directly estimate a patient's cardiovascular risk when WCH or various types of dipping are suspected. ${ }^{2}$ Clinical management of hypertension as routinely practised may be changing.

Donald V Powers, MD Delaware County Memorial Hospital Drexel Hill, Pennsyluania, USA

1 Pickering TG, Coats A, Mallion JM, et al. Blood Press Monit 1999;4..333-41. 'Brien F Pickering T, et al. Am J Hypertens 